article was in 'Keer to Kent' the magazine of the Silverdale and Arnside Area of Outstanding Natural Beauty. I have permission from his widow, Dr Ruth Pollock, and the editor of 'Keer to Kent' to reproduce the article, which follows, as it adds much to this section about ticks.

This completes my anecdotal account but perhaps I should finish with two lines from the hymn:

'All things bright and beautiful all creatures great and small'

Correspondence to: John Houghton Chippendale MB, ChB, D.Obst RCOG jjchip@tiscali.co.uk

\section{REFERENCES}

1. Chippendale JH. National Service RAMC 1959-1961. MBM7;4(6);197-9.

Chippendale JH. We'd better call the doctor. 2010 MBM7; 6(2); 45-9.

2. Chippendale JH. A beekeeping boyhood. 1998 Yorkshire Journal; 22; 69-71. Also Phinn Gervase 2008 All Our Yesterdays; page 98.

3. Chippendale JH. 1962 and all that. 2007 MBMF; 5(6); 180-1.

4. Pollock B. The dangers of ticks and Lyme disease. 2004; Keer to Kent; 53(14).

\title{
The Dangers of Ticks and Lyme Disease
}

\section{Bernard Pollock}

A significant threat from an unsuspected source has recently been found to occur in our area. It is an infection called Lyme Disease. There is speculation that the incidence of this infection is increasing due to larger numbers of ticks as a result of global warming. This has potentially serious health implications for anyone engaged in outdoor activities within the Silverdale and Arnside Area of Outstanding Natural Beauty and beyond, when contact is made with vegetation carrying infected ticks. Awareness of this risk is, therefore, an important first step in the prevention of this infection.

Like so many of us, I have frequently removed ticks from my skin, without further thought, following outdoor exploits around Warton. Last May, however, I unexpectedly developed Lyme disease following a tick bite some weeks before. I remember that the original bite on my right shoulder did not heal as quickly as previous ones and remained persistently itchy for some time.

One morning I awoke conscious of a painful right shoulder joint, a mild fever, generalized aching of the body and a feeling of utter exhaustion. These are apparently secondary symptoms, and the original tick bite had already become red, with an expanding circular rash like a red ring of 6 inches diameter around it (the skin between the bite and the red ring being relatively pale). This skin eruption has been described as Erythema migrans (giving a 'Bull's Eye' appearance), and the suspicion that this was Lyme disease was soon confirmed, both clinically and later with a serum blood test. I was fortunate that the treatment, which had been started promptly, proved to be successful.

\section{CAUSE}

Lyme Disease, or Lyme borreliosis, is carried by the sheep tick, Ixodes ricinus, amongst others. It is caused by a spirochaetal bacterium carried in the mid-gut of infected ticks. The disease was first recognised and described in November 1975 at Old Lyme, Connecticut, USA, although it is thought to have been present in England for at least 100 years.

The tick, which is carried by a number of host animals, including deer and pheasants, has three stages of development. The eggs found in leaf litter hatch into larvae and are picked up by birds and rodents as hosts who provide a meal of blood. The larvae then develop into nymphs, which, being more mobile, crawl to the ends of grasses, and other low vegetation, where they latch onto passing host animals including humans, to take the next blood meal and so reach the adult reproductive stage. After mating, the female falls to the ground, where she lays her eggs, to repeat the cycle.

Most commonly it is at the nymph stage, especially during spring and early summer when ticks are active feeders, that they affect humans. As they are so small, at first they are easy to overlook and can be difficult to detect. The risk to human health comes from those particular ticks that carry the bacterium Borrelia burgdorferi. Another difficulty is that more than one tick-borne disease can be carried, making diagnosis more of a problem.

\section{PREVENTION}

The most important factor is to be aware of the existence of Lyme disease in this area. Prevention is of course always better than cure and there are some preventive measures which should be considered before venturing out on walks off the beaten track or in other 'field' activities. These include the following:-

- Wear light-coloured clothes, so that ticks, if they accidentally land, can be seen more easily and removed before they reach the skin.

- Wear a long-sleeved shirt and long trousers tucked into the socks, to keep as much of the skin covered as possible.

- Use insect repellent (with care) to deter ticks.

- After a day out in the countryside, strip off, shower and inspect your skin thoroughly, to ensure that no tick has been overlooked.

If a tick is discovered, it is crucial to remove it sooner rather than later. Although other methods are possible, the tick, usually a small nymph, can be removed by using fine tweezers. It should be picked up as close to your skin as possible so as not to squeeze the contents of the tick into 
your skin. This is important if the tick is infected. Then a firm and confident twisting pull will usually remove the tick cleanly. Even if some mouth parts of the tick are left imbedded, these are usually extruded later when healing takes place. Then some antiseptic can be applied with possibly a dressing.

It is said that if an infected tick is removed within 24 hours of pick-up then there is less chance of Lyme disease developing even if Borrelia has been found in tick saliva. However, after 24-48 hours the spirochaete bacterium can enter the blood stream of the host for infection to begin. Early removal is clearly essential for successful prevention. After removal the tick should be kept in a suitable container, in case future analysis should be necessary.

\section{DANGERS}

With early diagnosis by straightforward tests, simple antibiotic treatment is usually effective. But if the infection should become established and spread, then it can cause such conditions as muscle palsy and other neurological manifestations, arthritis, heart complications, etc. Occasionally, Lyme disease is not clearly defined at first and presents later in a more disseminated form, which can be more difficult to treat. Unfortunately, a previous infection does not convey immunity from further infections. It is, therefore, not a disease to be taken lightly and needs to be thought of seriously when you are out and about.

In short, be aware of the possibility of Lyme disease, by dressing sensibly to protect the skin from ticks, and by taking the earliest possible action in removing any tick that succeeds in penetrating the defences. If symptoms do develop, advice should be sought from your doctor as soon as possible.

It won't surprise you that I, for one, will be very much on my guard in future. After all: 'Once bitten, twice shy!'

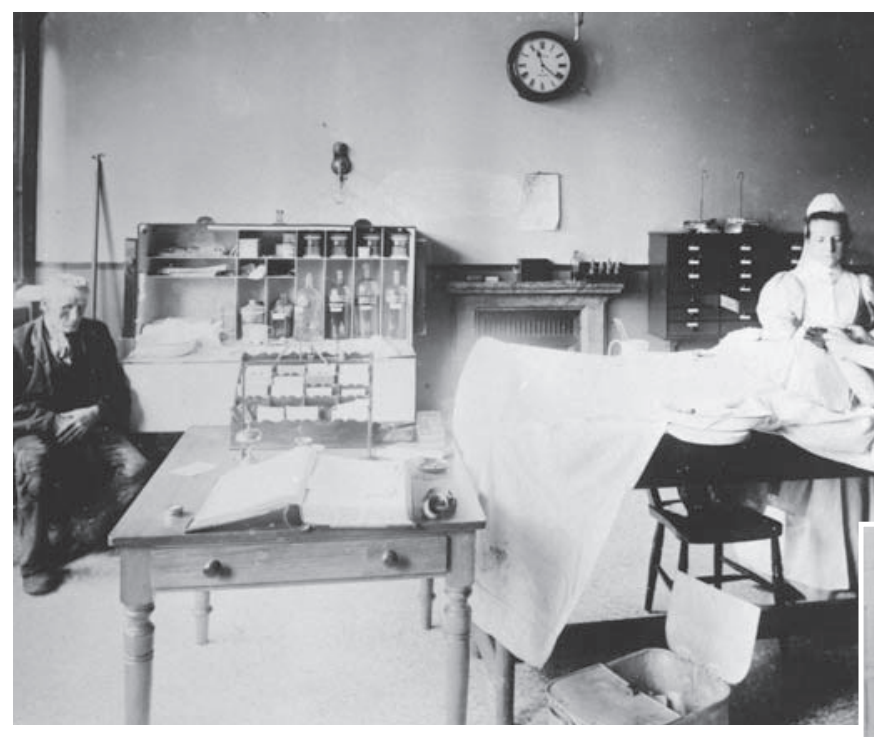

RLI 1897

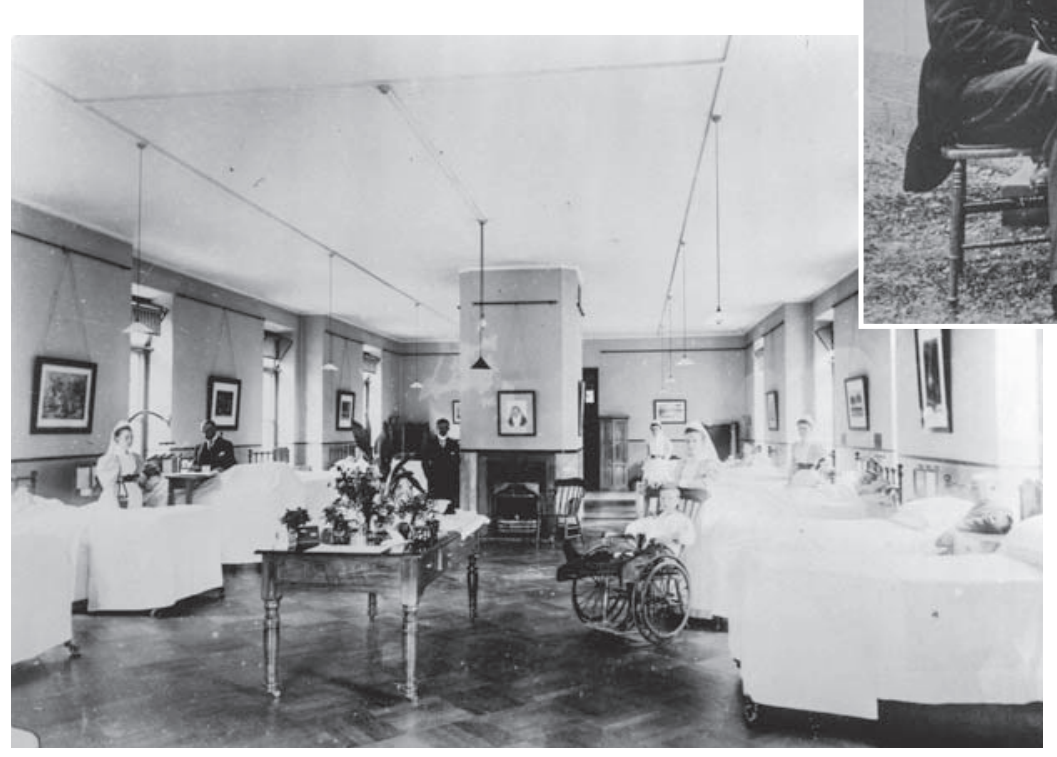

Photos were provided by Mr Bryan Rhodes, Orthopaedic surgeon, RLI 